\title{
Jaime Torres Bodet. Comentarista de las artes de Italia ${ }^{1}$
}

\author{
HÉCtor PEREa \\ Universidad Nacional Autónoma de México \\ perea28@hotmail.com
}

\begin{abstract}
Resumen: En este artículo se aborda la crítica artística de Jaime Torres Bodet. Se estudian sobre todo los ensayos y comentarios dedicados al arte italiano y, en particular, a la vida y obra de Leonardo da Vinci y al desenvolvimiento del Renacimiento veneciano. La pasión viajera, que llevó al escritor por Italia y Europa en general, así como el trabajo desarrollado como director general de la UNESCO, influyeron de manera determinante en sus escritos dentro del campo tratado.
\end{abstract}

Palabras Clave: Jaime Torres Bodet; literatura mexicana; crítica de arte; arte italiano; diplomacia mexicana.

АвSTRACT: The art criticism and creative writings by Jaime Torres Bodet are analized in this article. The essay is focused on Bodet's criticism and notes about Italian art, mainly on Leonardo Da Vinci's life and Venetian Renaissance. It is recognized that his travels around Italy and Europe and his work as UNESCo's Director-General would influence his writings on this subject.

KeYwORDs: Jaime Torres Bodet; mexican literature; art criticism; italian art; mexican diplomacy.

FECHA DE RECEPCIÓN: 24 de abril de 2015

FECHA DE ACEPTACIÓN: 25 de septiembre de 2015

Dodríamos decir que el primer acercamiento al comentario del arte lo tuvo Jaime Torres Bodet entre 1925 y 1926, cuando ejerció la crítica cinematográfica al parejo de sus labores docentes. A diferencia de otros articulistas que lo veían como una diversión vulgar, el escritor consideraba ya al cine como un "arte de lo transitorio, de lo cotidiano" (1986: 158). De hecho en la revista Contemporáneos, además de él, Xavier Villaurrutia se interesó en este medio como un fenómeno rico de

${ }^{1}$ Este trabajo se realizó gracias a un apoyo de la Dirección General de Asuntos del Personal Académico-PAspa. 
analizar. Y ambos, junto con Carlos Pellicer y Jorge Cuesta, encontrarían en el arte elementos jugosamente atractivos.

Comentarista de la industria en su etapa silente — quizá la más pura-, al igual que dos lustros antes Alfonso Reyes y Martín Luis Guzmán, sus antecesores en este campo, Torres Bodet llegaría a exigir de un cine en claro proceso de maduración la filmación de obras de calidad y, lejos de influencias espurias, verdaderamente cinematográficas.

Mientras Luis Buñuel organizaba por esos años, en la Residencia de Estudiantes de Madrid, ciclos de cine vanguardista, Celuloide, seudónimo usado por Torres Bodet en la sección La Cinta de Plata, lo que hizo en México fue promover un plan mucho más ambicioso: la creación de una filmoteca que pusiera al alcance de los buenos aficionados la historia de este arte, que ya contaba con algunos auténticos clásicos.

Pero en cuanto a la creación plástica, ¿cuál sería la vinculación entre esta postura dirigida al cuidado y exhibición ordenada de las cintas y el arte con mayúsculas? La proximidad estaría, a mi modo de ver, en la curiosa forma en que el autor de Biombo definió este "salón" de resguardo y proyección de las películas. Pues él lo concebía como una biblioteca de filmes que fuera al mismo tiempo el "museo de un arte vivo". Inevitable recordar aquí el "museo dinámico" inventado por Alfonso Reyes en 1924, o el "imaginario", hecho una realidad de papel por André Malraux en los ańos cincuenta del siglo pasado.

Frente a la idea clásica seguida por escritores-viajeros como Alberto J. Pani, Genaro Estrada, Isidro Fabela o Artemio de Valle-Arizpe, coleccionistas plenos de lo europeo y lo americano todos ellos, y en los que la mirada original y la consiguiente exhibición privada consumían su pasión por el arte, y coincidente más bien con la postura adoptada por Octavio Paz, ${ }^{2}$ Jaime Torres Bodet vería el coleccionismo cosmopolita como una suerte de acumulación virtual de las obras preferidas o inquietantes para su disfrute por duplicado.

Una primera etapa de ese gozo se consumía para él frente al objeto real y la emoción producida por la vista directa del mismo — hecho que recuerda, en cierta forma, la postura de Martín Luis Guzmán-. La segunda se desprendería de otro proceso muy distinto: el de reaproximación a la obra. Posible a través del comentario por escrito, del texto

${ }^{2}$ Alfonso Reyes proponía conservar sin disecar: "porque no todos tenemos aficiones de coleccionador, ni siempre es tolerable ver la vida en restos de naufragio" (292). 
elaborado a partir de una nueva mirada al objeto y a las circunstancias que lo rodeaban en el recuerdo.

En anticipo o modelo involuntario de Miradas subversivas (1997), el libro muy posterior de Sergio Fernández, Torres Bodet reuniría una parte medular de sus gustos y comentarios sobre arte en el volumen Maestros venecianos. Homenaje en cierta forma a la ciudad, como el de Fernández — aunque el más reciente bajo un pretexto sorjuanesco-, en las páginas de este volumen Torres Bodet haría un recorrido erudito sobre la historia de Venecia, su arquitectura y sus pintores. Miguel Ángel Flores observa que en el volumen Torres Bodet muestra "la asimilación de las lecturas de Baudelaire y Paul Valéry” (123). Pero también remite a las palabras del propio autor que, en entrevista con Emmanuel Carballo, señalaba la imposibilidad de ejercer la crítica de arte con el mismo nivel de precisión técnica que los profesionales de la misma. "En el libro que usted alude — decía entonces a Carballo— traté únicamente de describir mis emociones personales frente a un conjunto de artistas que hicieron del color una poesía expresiva" (Carballo: 282).

A pesar de volcarse de lleno en el tema, y de la enorme riqueza de propuestas, al lector de Maestros venecianos no dejará de parecerle, más que el ensayo producto de un viaje — sensación efectivamente presente en el de Fernández- y con ideas originales, uno realizado a partir de muchos recorridos y, sobre todo, de otros libros. Un compendio, la eterna reconstrucción del entorno basada en versiones previas, canonizadas en su mayor parte. Aun así, Maestros venecianos contiene páginas de gran calidad literaria que demuestran el interés auténtico por el arte y la sensibilidad que Torres Bodet fue afinando durante sus años europeos.

En cuanto al arte como un hecho universal, sin embargo, Torres Bodet no se limitó a gozar y escribir sobre Tintoretto, el Veronés o el manierista Lorenzo Lotto, sino que indagó además en la pintura y la vida de artistas tan disímbolos como Leonardo, Rubens, Memling o Delacroix. A partir de la comparación entre sus temperamentos y obras llegaría a conclusiones bellas y asombrosas sobre la creación de todos ellos.

El caso que más apasionó al escritor fue quizá el de Leonardo, a quien se acercó procurando limpiar su imagen y obra de todo prejuicio y lugar común. Dos pequeños ensayos surgirían de su interés por este multifacético artista. Uno, libre y apasionado. El otro, más amplio y en el que recuperaba algunas de las líneas, las más brillantes, del primero, 
sería concebido como texto oficial para su lectura en el poblado de Vinci, en 1952, durante la ceremonia conmemorativa del V Centenario del Nacimiento de Leonardo. Torres Bodet iba aún como director general de la unESCO, cargo que dejaría ese mismo año. Por las características de ambos escritos me adentraré más bien en el primero, que es en realidad una pequeña sección del apartado XL, titulado "París, 1929", de sus memorias Tiempo de arena.

Encuentro al menos tres ideas relevantes en las páginas que Torres Bodet dedicó, durante esa primera visita al Louvre, a ver obras originales. ${ }^{3}$ En las mismas aprovechaba para señalar que hasta esos años Rafael, Botticelli y Leonardo habían sido sus artistas favoritos. Una era la necesaria rectificación frente a las interpretaciones críticas que habían imaginado "un Leonardo abstracto, todo ensueño y fervor teóricos, inventor de fantasías irrealizables, luz de llama que estérilmente a sí misma consumía" (Torres Bodet 1995: 345). Ya para ese entonces, finales de los ańos veinte y mucho antes de la Segunda Guerra Mundial, Leonardo debía verse, al contrario, como un "hombre múltiple" en el que habían fraternizado y se habían enlazado constantemente "las ciencias y la técnica, la literatura y el arte, el naturalismo más riguroso y el idealismo más encendido".

Lo anterior tendría que ver también con lo que el propio escritor veía como diferencia entre algunos pintores retratistas de diversas épocas y Leonardo. Torres Bodet consideraba que mientras otros artistas trataban de idealizar sus modelos, Leonardo lo que conseguía era materializarlos. Los retratos del pintor de Vinci, y Torres Bodet remitía desde luego a la Gioconda y a la Virgen de las rocas, del Louvre y la National Gallery de Londres respectivamente, aunque se señalara con insistencia, no eran tan perfectos como otros "en los que la materia se encuentra reproducida con más suave delectación”. Aquí el autor pensaba muy probablemente en algunos ejemplos del arte flamenco. Al contrario de los pintores que pretendían lograr una vista de sus personajes, Leonardo, adoptando una actitud de mucha más hondura psicológica, había buscado capturar la visión de los suyos. Puntualizaba Torres Bodet:

\footnotetext{
${ }^{3}$ En el apartado en que comentaba la plástica de Delacroix, señalaría la deformación sensible e interpretativa que implicaba el conocimiento de las pinturas por intermedio de reproducciones en blanco y negro.
} 
La obra resume, en toda la amplitud del vocablo, una encarnación; esto es: un encantamiento. Suele aplicarse el término "verosímil" a los retratos de otros pintores. Los del autor de La Cena son más que eso: son verdaderos. El artista, en ellos, no nos da sólo una semblanza del individuo que representa. Su propósito es otro. Merced a esfuerzos en que la técnica adquiere el valor de un conjuro mítico, crea un ser inmortal. Sus pinceles, más que inmovilizar el rostro de una mujer, dan forma a esas posibilidades excepcionales que raras veces demuestra la biografía de una persona y, con estudiada arbitrariedad, utiliza los elementos de la belleza humana para inventar una vida nueva, de evidencia lírica superior (1995: 344).

Sin sugerir con esto ningún rasgo de inferioridad, sino más bien la clara diferencia existente entre una y otra concepción del retrato, Torres Bodet mencionaría los siguientes casos de obras en las que el pintor había conseguido una vista extraordinaria del personaje abordado, pero sin lograr extraer del mismo una visión. La María Luisa, de Goya, era ella misma; el Castiglione, de Rafael, no era más que El Cortesano. Lo alcanzado por Leonardo en sus retratos, más allá de la propia calidad de la pintura, tenía repercusiones en diferentes campos y encontraba sintonía con otras grandes obras. Aseguraba Torres Bodet: "Mas, para la evolución de las artes plásticas, constituye la imagen de la Gioconda lo que, para la poesía, la figura de Beatriz en los cantos de la Comedia. Beatriz es la Teología. La Gioconda, el Renacimiento”.

El tercer apunte que, a mi modo de ver, valdría la pena recuperar dentro de las opiniones que sobre diversos aspectos del arte y la personalidad de Leonardo concluyó Torres Bodet, es el relacionado con la universalidad de su mirada y de su acción.

El autor de Fervor confesaba haber tenido dificultades en juzgar a Leonardo como creador en un solo campo, "porque todo lo fue en grado egregio". Y por todo quería decir como pintor, escultor y arquitecto. Pero también como naturalista. Una característica que, en opinión de Torres Bodet, diferenciaría a Leonardo de otros artistas plurales era que él ejerció sus distintos oficios y consumió sus variados intereses simultáneamente y a lo largo de toda su vida. No fue alguien que pasara de una etapa a otra, que fuera mudando de gustos y pasiones por capricho o por azar. Además de creador en los campos de la pintura o la escultura, el artista de Vinci había sido "pacifista y experto en balística, botánico 
y geógrafo, fisiólogo y matemático, tratadista de la pintura y de la mecánica del vuelo, ¿¿ónde circunscribir a Leonardo si no es en la imagen total del hombre?" (345), remataba Torres Bodet. Para a continuación arriesgar una interpretación libre y compleja de la siguiente aseveración, sintética en extremo, de Leonardo: "Es fácil ser universal". Estas palabras del renacentista, sencillas en apariencia y más bien engañosas, consideradas dentro del amplio contexto de su creación artística y su múltiple actividad científica y tecnológica, llevarían a Torres Bodet a la siguiente conclusión: Leonardo

probablemente no aludía a una universalidad de enumeración, sino a la capacidad de considerar cada objeto en relación con sus causas y con sus leyes, de ubicarlo en el sitio que ocupa dentro de la naturaleza o la sociedad y descubrir la función que ejerce y los servicios que puede prestar al hombre. Ser universal no es, sin duda, saberlo todo. Es, más bien, adiestrarse a fin de percibir cada circunstancia desde el mayor número posible de puntos de vista y hallar así, en cada acontecimiento, la esencia que lo vincula con el conjunto del universo (345).

La imagen que Torres Bodet se construyó, a manera de ejemplo y medida personal, de Leonardo, fue muy similar a la que él mismo tuvo del arte en general. El abate González de Mendoza, con la intención de hacer su propio retrato del escritor como promotor de las artes, entresacaría de uno de los discursos de Torres Bodet las siguientes palabras, suma de su pensamiento sobre el sentido y la proporción humana y en particular de la creación artística: "El arte verdaderamente grande coincide con las dimensiones cabales de la humanidad. Se extravía tan pronto como, por las exigencias de un refinamiento arbitrario, sacrifica su vocación de expresar el corazón de cada cual y de conmover despertando en su fondo, al mismo tiempo, el sentido de la belleza" (González de Mendoza: 312).

Un hecho señalado antes, y que afectaría a muchos de los autores mexicanos anteriores o contemporáneos de Torres Bodet, fue el tener, casi irremediablemente, un contacto inicial con las obras a través de reproducciones sin relación auténtica de tamaño o color con los originales. En el caso del acercamiento a la pintura de Eugène Delacroix este antecedente resultaría tan claro que la primera visita al Louvre llevó a Torres Bodet a considerar como "un descubrimiento" la vista en directo 
de los cuadros del pintor de Charenton-Saint-Maurice. ${ }^{4}$ La otra deformación, la de la interpretación vital de Delacroix, el escritor la había padecido por medio de los testimonios de George Sand y de Chopin, amigos íntimos del pintor. En esto el comentario de Torres Bodet remitía a sus opiniones sobre la crítica histórica a la obra y a la vida de Leonardo.

La impresión que aquella visita dejó en el escritor resultó en verdad extrema, como podemos ver en las líneas que al respecto escribió en Tiempo de arena. En los lienzos "inmensos" de Delacroix, Torres Bodet descubría que sus personajes manifestaban "la despótica voluntad de ser" (1995: 347). En esto, sus composiciones plásticas eran totalmente distintas de las de Rubens o de cualquiera de los grandes venecianos, "los campeones de la voluptuosidad y del goce plástico". Esta muestra de "deseo, deseo" y de franca libertad — de traición al artista- que presumían los seres humanos en las telas del francés contrastaba con la voluptuosidad actuada y la riqueza de atavío de los personajes en los cuadros mitológicos de Rubens. La diferencia se hacía clara en cuanto uno descubría la patente sumisión de estas figuras al poder del creador. Por lo mismo, a causa de ese sometimiento, el deseo que actuaban no era el suyo propio, sino "sólo el eco de la voluntad poderosa del artista".

La perfecta valoración en peso de los objetos y elementos compositivos en los cuadros del Veronés, Ticiano o Giorgione, "esta aceptación tranquila del universo" sería otra demostración del abismo que separaba una concepción de otra en cuanto a la creación plástica. "La furia sin dicha” fue característica exclusiva de los óleos de Delacroix según Torres Bodet. El escritor se detenía en una amplia descripción del cuadro La muerte de Sardanápalo, compendio de las características plásticas y dramáticas observadas por el miembro de Contemporáneos en los óleos del pintor romántico. Repito, la mencionada "aceptación tranquila del universo", patente en los cuadros de los venecianos, era para Torres Bodet el mejor ejemplo de lo que separaba esta concepción plástica y humana de la del francés:

${ }^{4}$ ¿A quién no le ha pasado lo mismo al enfrentar la primera mirada auténtica, en la Galería de la Academia de Venecia, del Banquete en la casa de Levi (1573), de Paolo Veronés — pintura de más de cinco metros de alto por 12 de largo-, después de haberla apenas entrevisto en cualquier libro de arte? 
Ningún minuto le parece a él bastante solemne, ninguna agonía de príncipe suficientemente rodeada de pompas. Evoco, por ejemplo, La muerte de Sardanápalo. Extendido sobre un gigantesco diván, con un codo apoyado en el almohadón y la cabeza en la palma de la mano, el rey mira desaparecer a sus plantas todos los goces que empobrecieron su vida. Las favoritas le imploran, con unos desnudos que gritan más que sus labios, mientras los esbirros les hunden, en la nave de las gargantas, curvos alfanjes. Me asombró, por singularmente verboso, a la izquierda inferior del cuadro, el grupo en que un esclavo conduce a los caballos más finos hasta el lecho de su señor. Un bazar, en el que los más suntuosos objetos no consiguen darnos el tono de la riqueza, una melodía de formas que se satisface a menudo con la estridencia que la destruye; un tumulto de nucas, torsos, crines, espaldas, en que los blancos no se acarician, ni los verdes se integran, ni los cárdenos se contrastan... Nada podía demostrarme mejor que ese falso Rubens lo que era, en 1827, el auténtico Delacroix (347-348).

La apreciación de este cuadro de considerable formato había sugerido de inmediato la visita a la sala Rubens, del Louvre, que contiene la serie encargada al barroco flamenco por la reina María de Médici para decorar el Palacio de Luxemburgo.

Para Torres Bodet este pintor, al contrario de lo escrito por Baudelaire — "Río de olvido, Rubens, jardín de la pereza”-, había sido un "colorista insigne, entre cuyos dedos la luz resulta siempre cálida y modelable". Artista múltiple, su creación resultaba la mejor muestra de sinestesia - “oye, palpa e incluso huele con la mirada”. El universo de Rubens era un torbellino para el espectador; su equilibrio un vértigo y, su desnudez, una metáfora más en opinión de Torres Bodet. Lejos de Góngora o Cervantes, el mexicano encontraba que, sin embargo, la pintura de Rubens tenía una proximidad barroca con la prosa grandilocuente del religioso francés Jacobo Bossuet:

Un mismo ritmo ordena los pliegues en los mantos de sus monarcas y en las peroraciones del Obispo de Meaux; lujo ceremonioso de la Contrarreforma; música de una edad que coincide, en política, con el absolutismo, y con la cúpula en arquitectura; triunfo del exordio y de la perífrasis, de la oración fúnebre y de la biografía de caballete, de los episodios gratos a la memoria de María de Médicis y del elogio de Turenne en las exequias del Gran Conde (348). 
Torres Bodet defendía la abundancia en las escenas de Rubens, que consideraba riqueza más que simple enumeración, y se mostraba en completo desacuerdo con Baudelaire, quien, además de lo ya citado, había llegado al extremo de llamar "patán vestido de satín" al pintor. Frente a esta opinión superficial, el mexicano esgrimía la siguiente y compleja interpretación comparativa:

Anterior a la orquesta moderna (que no había de alcanzar su cabal volumen sino 150 años más adelante), su obra promete ya, en el umbral del siglo XvII, una versión instrumentada de la existencia. Suenan, como címbalos, los cobres y los rojos de sus otońos; gimen, como flautas, los anaranjados de sus auroras, y cantan, como violas, los verdes de sus estíos. Lo que en los atriles del Ticiano y de Rafael es sonata - o cuarteto para instrumentos de cuerda - adquiere, en las pinturas de Rubens, complejidad y ambiciones de sinfonía. A menudo, la limpidez de las voces se ahoga. Pero el conjunto gana en sonoridad lo que pierde en pureza y en transparencia (349).

Rubens, en las colecciones de los museos, parecía tener una función precisa. Su mundo, "paraíso terrenal de la indulgencia y de la salud, en el cual la penetración psicológica no es psicoanálisis”, se presentaba ante uno como un oasis, frente al agobio que podían provocar en el visitante las tentaciones del Bosco, las mitologías de Poussin, los inviernos de Bruegel o las efusiones domésticas del holandés Jan Steen. Pero sobre todo, y en un nivel quizá superior al anterior, uno volvía los ojos a este universo de placidez después de haber enfrentado la imparcialidad velazqueña, el pesimismo de Rembrandt, el sarcasmo de Goya o la audacia de Miguel Ángel.

$\mathrm{Y}$ es que en las pinturas del flamenco ni el amanecer era "un estado de alma, ni amargura la gloria, ni anemia la palidez". Uno de los elementos a tomar en cuenta para valorar en toda su amplitud las pinturas de Rubens era para Torres Bodet el tiempo. Pues, "bajo su mágica pincelada", "todo huye, fluye, corre, pasa, escapa, vuela, florece, envejece, agoniza, renace, se recupera...”.

Rubens era espléndidamente simpático con todos los elementos que incluía en sus obras, ya fueran estos seres humanos, animales u objetos inanimados. Con todo y la elegancia y peso que le había dado su condición aristocrática de embajador, cortesano y amigo de personalidades 
de la iglesia o de la realeza, Rubens fue, como pintor, "una de las fuerzas más vigorosas de esa democracia de la sensibilidad" que, en opinión de Torres Bodet, precede a la democracia política.

Éste y otros pintores, sobre todo de la escuela barroca española, merecieron comentarios al margen, citas, trazos o comparaciones literarias del autor en Tiempo de arena y en distintas obras de recuerdos. Una mujer en el tren portaría un escote a lo Rubens y una "cabeza indulgente, frágil y astuta, de Leonardo" (382). En otro momento, a continuación de la descripción del San Ildefonso, pintura del Greco colgada en la parroquia del Hospital de la Caridad de Illescas en la que "ningún ritmo demasiado trágico la disloca" y, cabría destacar, donde el centro compositivo no era la hermosa cabeza de la Virgen sino, muy al contrario, la mano que lleva la pluma - "delgada mano en que la voluntad de una perspectiva ideal rompe toda regla de anatomía”-, Torres Bodet haría por escrito, bajo la clara influencia de lo visto recientemente, el siguiente bosquejo literario del paisaje, muy similar a otro en que "la miel del sol" se había transmutado en "las penumbras de Zurbarán" (382): "De Illescas a Toledo, el camino se llena de curvas, de lazos. A uno y a otro lado de la carretera comienza a ondular un cielo muy bajo, casi pintado de plata por la promesa de una ligerísima lluvia” (382).

Sobre las resonancias o similitudes que se dan entre la literatura y la pintura, en este caso las españolas, Torres Bodet acudiría a una sintonía observada por él. Este ejercicio, recordemos, lo practicó también en el caso de la pintura renacentista italiana:

Aunque el más hermoso libro español es, sin duda, la historia de Don Quijote, el madrileño más exigente sigue siendo Quevedo —y el más mordaz. Algo parecido acontece con la pintura. Puede insinuarse, en efecto, que Cervantes es para Velázquez como Quevedo para ese aragonés inmortal que se llamó Goya. Aquéllos expresan con mayor claridad los valores universales de Espańa. Éstos acuñan, en el metal de la Corte, el escudo dramático de Madrid (379).

Pero si Tiempo de arena es por muchos motivos un libro esencial para entender a partir de detalles - a la manera de cómo se usa el detalle de las obras en los libros de arte- la postura de Torres Bodet frente a la creación plástica y su comentario por escrito, sobre todo en relación con la cultura europea y de siglos anteriores al suyo, Equinoccio y aun Años 
contra el tiempo, dos volúmenes más de memorias, nos transmitirán también, en chispazos breves, esa nerviosa identificación que existió siempre entre el escritor y los pintores.

En el primero de estos dos cuadernos de bitácora Torres Bodet destacaba los paseos y consejos dados por Ángel Zárraga, pintor amigo suyo, así como de Alfonso Reyes y Martín Luis Guzmán. Los paseos por el Louvre en compañía de Marte R. Gómez sólo fueron mencionados al margen, por figurar con más amplitud en Tiempo de arena. Una presencia constante dentro de Equinoccio que me gustaría señalar es la del pintor barroco Jan Vermeer, especie de fetiche del autor ${ }^{5}$ estudiado mucho más adelante por Torres Bodet en Tiempo y memoria en la obra de Proust.

Vermeer fue una suerte de estribillo a lo largo de las páginas donde Torres Bodet contaba la llegada a La Haya para hacerse cargo de la Legación de México y los detalles subsecuentes de instalación y de vida cotidiana. Lo acompañaban su madre y su mujer. Detrás quedaban las experiencias española y francesa. Pero en realidad, además de los trabajos diplomáticos, sus actividades, aun sin tertulia a la madrileńa, serían prácticamente las mismas: visita a museos, largos paseos, lecturas y escritura. Si bien, por primera vez sintió el peso enorme de la extranjería.

Frente a una multitud de manifestaciones de la vida holandesa, Torres Bodet escogió dos pinturas que, aseguraba, le ayudarían como ningún otro elemento cultural, político o económico a descifrar el país. La primera fue Judith decapitando a Holofernes, de Caravaggio. La otra, Joven del turbante - o Joven con arete de perla, como también se le conoce-, que algunos críticos habían visto en papel de la Gioconda holandesa y otros, señalaba el autor, como tributo al retrato de Beatrice Cenci (1577-1599) atribuido al manierista Guido Reni ${ }^{6}$ que, por su carácter trágico y la belleza de la mujer, inspiraría páginas emocionadas de Percy B. Shelley, Stendhal o Artaud. Por otra parte, el cuadro de Vermeer llegaría a motivar a finales del siglo xx la novela homónima de Tracy Chevalier y ésta, a su vez, la película de Peter Webber (2003).

Torres Bodet, justo a causa del triste destino de la hermosa parricida romana, como también se le llamaba a la Cenci, no encontró sin

\footnotetext{
${ }^{5}$ Así como de Marcel Proust y Alfonso Reyes.

${ }^{6}$ Atribución puesta en duda hoy en día.
} 
embargo relación alguna entre los dos personajes femeninos. A pesar del relativo parecido entre las jóvenes y, sobre todo, entre los perfiles ideados por los artistas para que al girar el cuello las dos siguieran mirando de frente al pintor o, como seńala Torres Bodet, al "anónimo espectador".

¡Cuánta distancia existe entre ambas mujeres!... La italiana es, desde luego, sensualmente más atractiva. Por su parte, la muchacha holandesa resulta más delicada —y más inasible. Comprendí, al contemplarla, lo que había leído en una página de León Daudet: "Nunca puso pintor alguno, en la mirada de joven tan seductora, un agua azul tan lejana y tan refrescante, que hace pensar en los ojos de la tierna Cordelia, amorosamente descrita por Shakespeare" (1974: 54).

Torres Bodet era de los que aún ponían en duda la autoría de Vermeer en cuanto a La joven del turbante. ${ }^{8}$ De lo que sí tenía una certeza absoluta era de su belleza y de que guardaba un secreto celosamente. Misterio distinto, menos sibilino que el de la Gioconda; pero "éste, por familiar y modesto que nos parezca", no menos recóndito.

Poco más adelante, Torres Bodet, después de referirse a varios lienzos de Rembrandt y a manera de conclusión del apartado, volvería a la figura y a la obra de Vermeer. En esta ocasión, y para ejemplificar los marcados contrastes que observaba entre la obra de los dos holandeses, el escritor acudiría a una tela de 1670. Antes de describir la escena del pequeño cuadro, típica de Vermeer y distinta por el misterio que encierra de otras vistas de interiores propias de la pintura holandesa de entonces, Torres Bodet puntualizaba: "muy diversos de los valores de Rembrandt son los que muestra Vermeer en el hermético mundo de su Carta de amor" (57).

En una propuesta, fuera de lugar en apariencia, el autor comparaba esta pintura de apenas 44 x 38 centímetros con algunos de los frescos de Piero della Francesca. ¿Dónde veía Torres Bodet esta curiosa hermandad? No daba mayor explicación al respecto. Sólo aclaraba que en la obra de Vermeer no aparecerían, desde luego, ni Saba ni Salomón.

\footnotetext{
${ }^{7}$ Referencia obligada, por otro lado, a Velázquez, Las meninas, Foucault y Carlos Fuentes.

${ }^{8}$ La vacilación del escritor era bastante razonable. Mucho tiempo se había pensado que Muchacha leyendo una carta frente a la ventana se debía al pincel de Pieter de Hooch.
} 
De entre los frescos del pintor renacentista que pudieran compartir alguna característica con el cuadro del holandés pienso que el autor se refería a la serie pintada en la iglesia de San Francisco, en Arezzo, cerca de su ciudad natal. En primer lugar, porque Torres Bodet aportaba la clave principal: la ausencia del reino de Saba y el rey Salomón en el cuadro, presentes efectivamente en La leyenda de la Santa Cruz. Pero hilando más fino, podemos ver que en este trabajo muralístico de Della Francesca, compuesto por varios frescos de proporciones considerables, se da un sutil e intrincado juego de miradas y un manejo cromático y temporal parecidos, en lo que pudiera caber, a los que señalaba Torres Bodet en la Carta de amor. Así describía la escena el autor de Cripta:

La claridad de un ventanal —invisible para nosotros- alumbra el interior de una estrecha estancia donde una dama estaba tańendo un laúd. Dejó de tocar, para recibir la carta que una sirvienta le entrega. ¿Será una carta de amor? Así lo hacen suponer la sonrisa de la sirvienta y la mirada discreta —y, sin embargo, curiosa— de la señora... Pero ¿quién logrará jamás describir el verdadero instante de una pintura? Ventanas, cartas, instrumentos de música y, sobre los muros, mapas de clásicos litorales, se repiten en varias telas de Vermeer. $Y$, en realidad, nunca se repiten. Dentro de cada cuadro, son cosas únicas, por la sabiduría con que ordena cada detalle la elegancia cromática del pintor (57).

La otra tela que llamó especialmente la atención del diplomático dentro del Gabinete Real de Pinturas Mauritshuis fue una obra de Rembrandt. Torres Bodet no citaba en Equinoccio el título de la pintura, pero haría la siguiente descripción de la escena, que resulta más que suficiente para ubicarla: "es una de las más misteriosas de Rembrandt: la que representa a Saúl, cuando llora mientras toca el arpa David”. La obra es efectivamente David tocando el arpa para Saúl, de 1650-55, registrada hoy dentro de las colecciones del Städelsche Kunstinstitut y donde el pintor hacer destacar la figura del monarca, las formas del instrumento y la palma de la mano que lo ejecuta con una luz que, gracias al reflejo del manto, se vuelve rojiza y deja en penumbras todo lo demás. Es justo el momento en que la música del arpa —originalmente una cítara - mitiga la ira de Saúl. Torres Bodet haría el siguiente apunte en recuerdo de la escena: 
No pienso que la Biblia haya encontrado intérprete más tremendo. Todo en el cuadro es drama, desde la audacia ingenua del joven músico hasta la amarga resignación del rey que comprende su tránsito inevitable. Triunfará el joven, si lo permite Jehová. Perecerá el viejo rey. Se hará polvo el arpa sobre cuyas cuerdas apoya David sus dedos. Y se hará igualmente polvo el manto y el cetro que tanto pesan al desdichado monarca, arrepentido de ser más que de reinar (55).

Más allá de la descripción interpretativa de la escena concreta, la pintura llevaría a Torres Bodet a una reflexión personal, infortunadamente premonitoria dentro de su propia existencia.

El poeta tenía el recuerdo de la visita muchos años después de acontecida, lo cual podría haber justificado la postura que confesaba adoptar. Sin embargo, según subrayaba en el momento de escribir sobre esa época y ese tiempo en particular, ya desde entonces Torres Bodet se había sentido inclinado por uno de los dos personajes y por sus circunstancias muy concretas. Años después, la vista en el Metropolitan Museum of Art de Nueva York al Aristóteles del propio Rembrandt lo llevaría a "experimentar el mismo estremecimiento" tenido frente a la figura del Saúl del cuadro de La Haya. Así explicaba Torres Bodet el encuentro con esta pintura no siempre citada entre las principales del artista de Leiden:

Por la edad que tenía yo entonces, hubiera podido sentirme más solidario de la esperanza de David que de la ruina psicológica de Saúl. Mas no fue así. La poesía de Rembrandt me incitó a aquilatar la inutilidad de los triunfos que ambicionamos; cómo, con el viento que pasa, se desvanecen; cuán ilusorias son las coronas — materiales o inmateriales-, y hasta qué extremo quienes avanzan hacia la cumbre deben ya prepararse para la sima (55).

Las palabras con que Torres Bodet calificaba al filósofo que posa su mano sobre la cabeza de Homero en el cuadro del Metropolitan resultarían, transcurrido el tiempo, de un realismo asombroso y de un dramatismo extremo al aplicarse a la propia biografía del escritor:

En esa obra, ya no es el viejo quien sufre ante las esperanzas del joven. En el auge de su fortuna, el filósofo acaricia un busto de Homero y se apiada de la grandeza que semejante símbolo entrańa. Nada perdura. Por 
eso, el personaje de linajudo atavío que Rembrandt nombró Aristóteles advierte cómo — tarde o temprano- él también será cuando mucho un busto; es decir: la huella de una existencia que justifica nuestro respeto, pero debe inspirar también nuestra compasión (55-56).

Las ideas expresadas por Torres Bodet ante los cuadros del Rijkmuseum, visitado en multitud de ocasiones a partir del contacto inicial de esos días, son también muy sugerentes. El autor aclaraba que en relación con el acervo del museo más grande del país sólo mencionaría dentro de Equinoccio las obras que en ese momento, años después de la experiencia liminar, seguían fijando en su memoria "el recuerdo de una época tan pretérita”.

Torres Bodet se apoyaba en el arte para recrear la vida más allá del arte. Cuatro telas más de Rembrandt formaron parte de este conjunto emblemático de pinturas. Obras que mostraban su singularidad por duplicado. Eran hitos dentro de la historia del arte convencional. Pero también elementos clave en la reconstrucción de la vida particular del escritor. Se trataba de La lección de anatomía (1632), Los sindicos (1662), La novia judia (1666) y, "naturalmente", La ronda nocturna (1642). Sobre este último escribía Torres Bodet, en consonancia con su elección del poco frecuentado cuadro de David y Saúl:

Enciclopedias y guías conceden más importancia a La Ronda que a otras realizaciones del mismo autor. Admiro mucho la habilidad de su claroscuro, la luz que anima al fantasma de cada cuerpo, el halo de cada rostro y el misterio rítmico del conjunto. Pero me inquieta un poco el virtuosismo del cuadro entero. Y me atrevería a afirmar que La Ronda de Noche no es la obra de Rembrandt que más me agrade (56).

Frente al cuadro más mencionado de Rembrandt, tanto por su importancia plástica como por diversas anécdotas que han rodeado su existencia, Torres Bodet prefería La novia judía, pintura admirada a lo largo del tiempo por varios artistas entre los que se encontraba Vincent Van Gogh.

La pintura lo impactaba por ser "tan dramática en su ternura y tan exenta de artificios escénicos deleznables". En esta obra que muestra a una pareja de amantes, "el artista es el hombre, y la mujer es la vida", sintetizaba Torres Bodet. Para luego agregar: "al acariciarla, sabe el hom- 
bre perfectamente que no poseeremos nunca, de hecho, sino cuanto entreguemos, con plenitud, a la vida que nos fue dada”. Además del extraordinario juego de las miradas, que contiene la parte esencial de lo señalado por el escritor, en esta pintura resulta fuera de serie la amplísima gama de combinaciones cromáticas, de texturas y transparencias.

Para mayor contraste, el escritor daba a entender que antes que por La ronda su gusto se inclinaba todavía por otros rembrandts que guardaban las colecciones públicas del Louvre, el Prado o la National Gallery de Londres.

De vuelta al asunto de poder conocer a profundidad detalles esenciales de la vida de un pueblo por intermedio del arte de sus pintores, Torres Bodet remataba el paseo por las obras de estos dos holandeses singulares, que mostraron una concepción del arte absolutamente distintiva, con la siguiente afirmación: "Vermeer y Rembrandt me enseñaron a comprender: el primero, la poesía de la habitación holandesa, escenario de damas irrealizables, y, el segundo, la profundidad del dolor humano, con su grandeza y sus servidumbres, su pasión y su abnegación" (57).

El conocimiento del carácter holandés, sumado, en mi opinión, a la profundización en el aprendizaje de lo humano a través del arte, logros conseguidos en esos días de encuentro con lo ya visto en estampas y sentido como algo absolutamente nuevo, a partir de la experiencia directa, fue el anticipo de la primera aventura italiana de Torres Bodet. La incursión holandesa, y las anteriores en los museos de Madrid, París y Londres, escribía Torres Bodet en Equinoccio, "me habían enseñado a escuchar el silencio de las obras plásticas más gloriosas" (86).

La experiencia adquirida hasta entonces resultaría invaluable para enfrentar a los artistas, obras y entornos arquitectónicos y paisajísticos italianos, sólo pre vistos, de nueva cuenta, en reproducciones de regular calidad. O conocidos por su nombre. El apartado V de las memorias, "Italia a primera vista", fue pista de aterrizaje de los primeros deslumbres del arte italiano.

En un listado apretado, Torres Bodet señalaría las impresiones provocadas en él por el contacto inmediato con obras de Cimabue, Miguel Ángel, Rafael, Giotto, Simone Martini, Fra Angélico, los hermanos Lorenzetti, Della Francesca, Benozzo Gozzoli, Ghiberti, Signorelli, Tiziano, Tintoretto, Filippo Lippi, Botticelli. Este último le abriría una puerta hacia el recuerdo y las intenciones originales de obras literarias 
de juventud como Margarita de niebla o Estrella de un día. La vista de los frescos de Fra Angélico en el Convento de San Marcos, de Florencia, atraería las ideas descritas por Hipólito Taine y leídas por Torres Bodet en su juventud. La devoción, "tierna y sentimental" del monje-pintor que, en las palabras de Taine, llevaban a Fra Angélico a orar antes de elegir los pinceles que utilizaría y a llorar cuando pintaba el rostro de Cristo, conducirían a Torres Bodet a reflexionar sobre la enorme diferencia que existió en el siglo XV entre éste y otro monje de San Marcos, "el heroico Savonarola”, combativo filósofo y teólogo nacido en Ferrara.

$\mathrm{Al}$ escritor le admiraba la fuerza que adquiría una obra al ser vista en su original. Si por un lado el gusto por la pintura de Botticelli, conocida bajo las limitaciones de la reproducción impresa, seguía intocado para Torres Bodet, el encuentro directo con los frescos y las tablas del Giotto, Leonardo o Della Francesca había logrado engrosar la lista de artistas y pinturas por él preferidos. Asimismo, algunos palacios, villas, tumbas, iglesias de la Toscana, Roma, Nápoles o el Véneto fueron visitas obligadas y motivo de comentarios.

Uno de éstos, por cierto, sintético como pocos, resulta ejemplar en cuanto al proceso de sensibilización que, más allá de las particularidades del italiano, seguirían el gusto y los conocimientos de Torres Bodet en cuanto al arte en general. Al mencionar dos visitas a Florencia en distintas circunstancias diplomáticas y separadas por varios años, en las que el escritor había obviado primero para luego, finalmente, ceder al conocimiento de una iglesia, señalaría lo siguiente como de paso: "No fui, aquella vez, a la iglesia de Santa María del Carmine. La vería en 1950, cuando la UNESCO celebró en Florencia la quinta reunión de su Conferencia General. Sólo entonces lo comprendí: el puente, que lleva del Giotto a Miguel Ángel, pasa por Masaccio” (89).

Detrás de estas dos últimas líneas, sencillas y sin artificio, que se leen como si nada, se encierra todo un enfoque de la interpretación artística.

Menciones sueltas, párrafos, páginas completas dedicó Torres Bodet a analizar esculturas de Miguel Ángel y Donatello; óleos de Rafael, Tiziano, Tintoretto, Signorelli; las colecciones de la Galería Borghese, la veneciana Escuela de San Rocco y los Museos Vaticanos; los monumentos de la Roma antigua y los interiores de las iglesias más variadas de la capital italiana.

Con ser el resultado de primeras impresiones luego reelaboradas en función del libro Equinoccio, estas menciones, más superficiales que 
profundas, ${ }^{9}$ son apenas una aproximación a ese estudio amplio y, ahora sí detallado, que Torres Bodet tituló Maestros venecianos.

Torres Bodet echaba una ojeada a la historia de la ciudad como anticipo al comentario sobre sus creadores. Repitiendo la fórmula sintética a que me referí cuando hablaba de los artistas que trabajaron en Florencia, el escritor se aproximó a la obra de los pintores venecianos con esta brevísima pero ilustrativa opinión sobre una de las caras de la ciudad de los canales: "la avidez voluptuosa de su pintura [...] Ésta nos lleva a los encantadores mitos de Tiépolo, a través del Ticiano y del Veronés. Pero nos conduce igualmente -si queremos seguirla en sus últimas consecuencias - hasta las iluminaciones del Greco, por el camino del Tintoretto" (1995: 807).

En estas breves ideas, el autor de Cripta comprimía el devenir de una corriente pictórica que, por primera vez en su obra ensayística, motivó la creación de un libro completo.

Torres Bodet realizaría a partir de este punto un recorrido exhaustivo sobre la historia de esta escuela artística. Abarcó desde la creación en mosaico importada de Bizancio, visible sobre todo en San Marcos, hasta los trabajos sobre tela del siglo xviII, momento ya de decadencia de la ciudad. No olvidaría, desde luego, la referencia a obras realizadas sobre madera.

Basado en autores y en la reproducción de obras, pero también en recuerdos de primera mano, Torres Bodet hizo desfilar en sus páginas multitud de nombres y referencias artísticas, arquitectónicas y literarias. Entre los escritores y especialistas que citaba en Maestros venecianos se encuentran desde Proust hasta Ruskin, de Burckhardt a Vasari.

A los pintores optó por enmarcarlos en grupos. Así, y con objeto de reforzar sus comentarios con los contrastes y complementos que descubría entre uno y otro, a Jacopo Bellini lo estudió junto con Carpaccio, Giorgione y Ticiano. Al Tintoretto lo aproximó al Veronés. A Sebastiano del Piombo lo consideró al lado de Lorenzo Lotto, los dos Palma y Bassano.

Y mientras iba desplegando sus puntos de vista sobre todos estos grandes maestros, el diplomático iría mencionando muchísimos otros

${ }^{9}$ Después del primer recorrido, finalizado en Venecia, Torres Bodet se llegaría a preguntar: "¿habría visto y sentido, en verdad, Italia?” 
nombres y dejaría apuntes, varios de ellos verdaderamente emocionados, sobre cientos de obras de valor.

\section{BibliografíA}

Carballo, Emmanuel. Protagonistas de la literatura mexicana. México: Ediciones del Ermitaño / Editorial Diógenes, 1989.

Fernández, Sergio. Miradas subversivas. México: Consejo Nacional para la Cultura y las Artes, 1997 (El Guardagujas).

Flores, Miguel Ángel. "Jaime Torres Bodet: un recreo sobre las artes plásticas", en Rafael Olea Franco y Anthony Stanton (eds.). Los Contemporáneos en el laberinto de la crítica. México: El Colegio de México, 1994.

González de Mendoza, José María. "Torres Bodet: el impulsor de las artes”, en Ensayos selectos. México: Fondo de Cultura Económica, 1970.

Quirarte, Vicente. "El corazón en los ojos: pintura sonora de los Contemporáneos", en Rafael Olea Franco y Anthony Stanton (eds.). Los Contemporáneos en el laberinto de la crítica. México: El Colegio de México, 1994.

Reyes, Alfonso. "Contra el museo estático", en Obras completas, II. México: Fondo de Cultura Económica, 1995.

Torres Bodet, Jaime. La cinta de plata (crónica cinematográfica). México: Universidad Nacional Autónoma de México, 1986.

Torres Bodet, Jaime. Tiempo de arena y Maestros venecianos, en Obras escogidas. Poesía / autobiografía / ensayo. México: Fondo de Cultura Económica / El Colegio Nacional, 1995 (Letras Mexicanas).

Torres Bodet, Jaime. Años contra el tiempo. México: Editorial Porrúa, 1969.

Torres Bodet, Jaime. Equinoccio. México: Editorial Porrúa, 1974.

Torres Bodet, Jaime. Tiempo y memoria en la obra de Proust. México: Editorial Porrúa, 1967. 